\title{
MYANMAR
}

\section{Strengthening Smallholder Agriculture is Essential to Defend Food and Nutrition Security and Rural Livelihoods in Myanmar against the COVID-19 Threat}

\section{Elements for a Proactive Response}

\author{
Duncan Boughton, Joseph Goeb, Isabel Lambrecht, David Mather, and \\ Derek Headey
}

\begin{abstract}
There is an urgent need to anticipate the threat posed by COVID-19 to Myanmar's agricultural sector and to rural households that depend on farming for income and for food and nutrition security. We evaluate options to mitigate the threat and support farmers to prepare their land and plant their crops on time for the monsoon cropping season. Recognizing that no single intervention can address the full range of vulnerabilities faced by rural households, we evaluate the following options:

- Expansion of access to seasonal farm credit with extended loan repayment schedules;

- Limited agricultural input subsidies targeting certified seed; and

- Implementation of a cash transfer program to smallholder farmers.

Despite the high cost of a cash transfer program, there are good reasons to expect that the benefits of such support to farm households will outweigh program costs in monetary terms even more so if the economic benefits from the consequent lower incidence of malnutrition to which the program would contribute can be measured.
\end{abstract}

Myanmar, like many low-income countries in Southeast Asia, is extremely vulnerable to the human and economic consequences of COVID-19 (World Bank 2020; Hein and Minoletti 2020). The challenges facing high density urban and rural areas are linked in many ways - epidemiological, social, economic, and political. Households and individuals vary greatly in their vulnerabilities and coping mechanisms, even in the same geographical contexts. An effective mitigation strategy for Myanmar to counter the economic and food and nutrition security consequences of COVID-19 will require a variety of interventions over time, some broad and others targeted to specific sectors or vulnerable groups, that are implemented by a variety of organizations, including private businesses, civil society, and government at all levels.

As the largest employer in Myanmar and the foundation for the country's food and nutrition security, agriculture is a critical sector. Previous economic crises, such as the Asian financial crisis 
of 1997 and the global financial crisis in 2008, have shown that agriculture can be a potential shock absorber when urban or international migrants lose their jobs and return to their rural families. Myanmar farmers are planning now for the coming monsoon production season, making decisions on how much to invest in farming versus non-farm activities and on how much of their food crop production to hold in reserve for consumption needs during the "lean season". In the aggregate, farm household decisions taken in coming weeks will affect income and food and nutrition security outcomes for the local rural economy over at least the next 12 months, as well as the cost of food to urban consumers, foreign exchange earnings, and food price inflation. Given the short timeframe to influence farm household decisions for the upcoming monsoon growing season, what can the Ministry of Agriculture, Livestock, and Irrigation (MOALI) and other agricultural sector stakeholders in Myanmar do to support farm households to be successful despite the threat of COVID-19?

According to the most recent Myanmar Agricultural Census, 80 percent of Myanmar farms are operated by smallholders who cultivate for more than half the country's cropland. Despite their small size, these farms are an important source of employment for landless households due to the laborintensive nature of agriculture in Myanmar. Most smallholder farm households, and the neighbors they employ, are poor. They cannot afford a nutritious diet even in the absence of economic shocks (Mahrt et al. 2019). Taking account of experiences in previous crises (Block et al. 2004), this note focuses on evaluating interventions with the potential to improve the resilience of smallholder farmers in the face of imminent COVID-19-induced economic shocks, specifically to minimize adverse impacts on the food security and nutritional status of the rural population as a whole.

\section{Potential COVID-19 impact pathways on agriculture and rural livelihoods}

The immediate economic threat to rural areas posed by COVID-19 is the disruption of rural labor markets. More than three-quarters of Myanmar's population depends directly or indirectly on employment in the agricultural sector (World Bank 2020). Disruptions will affect the availability of labor (supply) and the ability of farm households to hire labor (demand). Initially, the potential availability of labor will increase as migrants return home from urban areas or overseas due to job losses due to COVID-19 in labor-intensive sectors, such as garment manufacturing or tourism. As the infection spreads to rural areas, however, individual households and their communities are likely to experience acute shortages of labor as family members become sick and need to be cared for.

In the short run, the largest impact of COVID-19 will not be on the availability of labor services, but on the ability of households to pay for them. This is because a third of Myanmar rural households depend on remittances from an estimated 3.8 million migrants. Due to COVID-19, the value of remittances to rural households can be expected to fall suddenly and for a prolonged period. Unless mitigated quickly, the loss of income from remittances will degrade the food and nutrition security of rural households as well as their ability to farm productively. Loss of income from remittances is not the only potential threat from COVID-19 that rural households face. Input supply delays due to border closures or obstacles to internal distribution, export restrictions that depress prices, and difficulties in access to domestic buyers, could all contribute to increased uncertainty and exacerbate farmers' fears of low profits from farming.

While COVID-19 will present many challenges for rural households in the coming months, the current shock of lost remittance income is occurring at the worst possible time of year, just when they need to invest in preparations for the coming monsoon growing season. Hired labor and mechanization services are essential, not only for total area planted but also for timeliness of planting, which determines yield potential. Combined with fears about low prices and returns to farming, negative income shocks will lead farmers to "tighten their purses" and cut back on investment in hired labor. These actions, in turn, will reduce the income of their neighbors who depend on such employment. Income from agricultural labor is an important strategy for poor landless and small farm households, especially during the "lean season" when they struggle to access a nutritious diet (Headey and Ecker 2013; de Wit and Noack 2019). 
To minimize losses to agricultural productivity and to prevent regression in the nutritional condition of vulnerable groups, such as women and children, it is important to act very quickly at a scale proportionate to the shock and with clear and effective public communication. Without such action, the economic and nutritional consequences of COVID-19 for the rural population of Myanmar will be even more severe and prolonged.

The most effective way to counter the effect of loss of remittance income and uncertainty due to COVID-19 is to increase the ability and motivation of farmers to invest in their farm production activities in the coming monsoon season. No single intervention can address all the complex impacts of COVID-19 on different types of rural households. This note examines the feasibility and potential effectiveness of three interventions to enable smallholder farmers to counter the threat of COVID-19 to rural livelihoods and to food and nutrition security:

- Expand access, increase flexibility, and lower the cost of Myanmar Agricultural Development Bank (MADB) loans;

- Improve the availability and affordability of agricultural inputs; and

- Provide a cash transfer to smallholder farmers.

The following sections discuss which types of intervention are most appropriate as an initial rapid response to help mitigate the economic consequences of COVID-19 for a broad range of rural households and key design factors for delivering timely, effective, and fiscally justified interventions. Our arguments draw on five years' research on agriculture and rural livelihoods in four agricultural zones of Myanmar funded by USAID and the Livelihoods and Food Security (LIFT) Fund ${ }^{1}$.

\section{Evaluation of interventions to mitigate COVID-19 impacts on agriculture}

The previous section highlighted the threat of COVID-19 to rural labor markets - specifically the difficulties smallholder farmers may face in paying for labor and mechanization services to plant crops in a timely way due to loss of remittance income and their concerns about the profitability of farming due to uncertainty about markets and prices. We now examine options to confront this threat, recognizing that a combination of interventions could be used.

\section{Increased flexibility and lower costs for Myanmar Agricultural Development Bank loans}

An expansion of MADB credit allocations to smallholder farmers will increase their ability to purchase labor or mechanization services, as well as other agricultural inputs. Credit allocations could be expanded in any of the following three ways: (1) an increase in the loan value per acre for different crops; (2) an increase in the cultivated area size limit beyond the current 10 acres; or (3) an increase in the number of smallholders eligible to receive seasonal credit. The following considerations are relevant to an inclusive and effective expansion of MADB credit:

- Many households among MADB's client base may not want to take on additional credit during a period of economic uncertainty even if they need additional financial resources to manage their household production and consumption. Recent high levels of price volatility for crops, such as paddy, pulses, maize and melons, mainly due to trade restrictions imposed by neighboring countries, have given farmers good reason to be risk averse. MADB can mitigate these concerns by extending the loan repayment period to allow farmers to sell produce later after harvest when prices are generally higher, and by reducing interest rates still further beyond the recent reduction from 8 percent to 7 percent per annum;

- Timeliness of loan disbursement is very important for the profitability of farm investments. It is important that any expansion of credit access not come at the expense of timely

\footnotetext{
${ }^{1}$ Research reports can be found at https://www.canr.msu.edu/fsp/countries/myanmar/publications
} 
disbursement of loans for the upcoming monsoon season. Similarly, the longer repayment periods for monsoon season loans should be done in a manner that will not delay disbursement of loans for the post-monsoon season when potential paddy yields are much higher due to increased sunlight and water control;

- Ensure that farmers can obtain credit for non-paddy crops as well as paddy;

- Expand geographical access to MADB credit. In southern Shan State for example, only 3 percent of farm households growing maize were able to receive loans from MADB compared to 65 percent of farm households in four Dry Zone townships studied (Magwe and Pwintbyu in Magwe Division, Myittha in Mandalay Division, and Budalin in Sagaing Division).

- In areas where Form 7 land use certificates have not been widely disseminated, MADB could increase the types of documentation that are acceptable to broaden credit eligibility.

- To facilitate social distancing to reduce the risk of COVID-19 transmission, MADB should accept electronic or physical copies of necessary documentation delivered to their offices. MADB should also explore the feasibility of accelerating mobile money transfers to clients with mobile money accounts.

Finally, in addition to smallholder farmers, agricultural businesses or small and medium enterprises (SME), such as machinery rental service providers, may also need expanded credit lines to ensure that the monsoon crop is planted and harvested in a timely way.

\section{Increased availability and affordability of agricultural inputs}

Ensuring the availability of agricultural inputs at retail dealerships is essential. With borders closed between Myanmar and India and between Myanmar and China, there is a risk that seed, fertilizer, and agro-chemicals are blocked from entry to the country. With restrictions on vehicle movements being put in place by some regional governments, internal distribution of inputs from wholesalers to retailers may also be delayed.

The importation and distribution of agricultural inputs should be considered essential activities for combatting the economic consequences of COVID-19 in the same way as medical supplies are considered essential to combatting its health consequences (IFPRI and MSU 2020). MOALI should maintain close communication with major input suppliers on the availability of agricultural inputs in their dealer networks and provide weekly updates to the Working Committee to Address the Impact of Coronavirus Disease 2019 (COVID-19) on the Country's Economy. Also, because input dealers, like MADB offices, are a potential COVID-19 transmission point, input dealers should have access to additional training resources via smartphone or TV to ensure social distancing by clients at their stores and should avoid multiple handling of stock by staff and clients to the extent possible.

One approach to making inputs more affordable to farmers is through a cost subsidy. So called "smart subsidies" use targeted voucher schemes that enable farmers to purchase inputs from dealers at a reduced price. The most effective schemes use electronic vouchers that are distributed to farmers and redeemed by retailers through mobile money systems. Such schemes usually require a preparation period of 12 to 18 months to pilot prior to roll out.

In the absence of enough time to design and implement a voucher system, government could negotiate directly with input importers and wholesalers to reduce the wholesale price of selected inputs and compensate them directly. Input retailers would then be required to pass the wholesale cost reduction on to their clients. Ensuring that the cost reduction is passed on to farmers is not straightforward. Governments in Asia and Africa that have tried this approach have experienced significant difficulties in ensuring that the subsidy is passed on from the fertilizer industry to farmers 
(Askhok and Naryanan 1995; Mather and Ndyetabula 2016). ${ }^{2}$ Also, unless the budget is large enough to provide a universal subsidy for a given type of fertilizer, the challenge of enforcing that the full amount of the subsidy is passed on to farmers becomes extremely difficult.

From the perspective of helping farmers establish healthy crops, making certified seed available at lower cost would be a cost-effective step with both short-term and long-term benefits. A recent study of the demand for quality seed in the Dry Zone found that lack of awareness of the benefits was the main reason for a lack of willingness among farmers to pay for improved quality seed (Boughton et al. 2020). A subsidy on certified seed would encourage farmers to plant higher quality seed and enable them to then evaluate the benefits for themselves. If farmers are convinced of the benefits of certified seed compared to their own saved seed, then they will continue to purchase such seed in the future even after the subsidy is removed. A focus on certified seed rather than agricultural inputs in general would also be easier for MOALI to negotiate due to the smaller number of suppliers involved and an existing platform for consultations with the private seed sector.

\section{Cash transfers to smallholder farmers}

Cash transfers targeted to smallholder farmers enable them to purchase agricultural inputs and services without taking on additional borrowing risk. Recent research on the impacts of cash transfers in Malawi and Senegal, for example, found higher levels of productivity (Ambler et al. 2017, forthcoming). Cash transfers to smallholder farmers can lead to increases in the use of hired agricultural labor, an important income source for landless or near-landless households, as well as machinery rental services, generating "welfare multipliers" (Filipski and Taylor 2012). The first step in considering a cash transfer to smallholder farmers is to understand the scale required. This requires information on the number of households potentially affected and the impact of COVID-19 on their incomes, especially the fall in remittances occurring just as preparations for the monsoon season begin. According to the 2010 Myanmar Census of Agriculture, there were almost 5 million farm households in Myanmar. Of this total, 5 percent had less than an acre, 49 percent had between 1 and 5 acres, and a further 27 percent had between 5 and 10 acres. A cash transfer targeted to households with 5 acres or less would reach 2.7 million farm households operating 6.4 million acres (20 percent of total cultivated land area). A cash transfer to households with 10 acres or less would expand the coverage to 4 million households operating 15.2 million acres (48 percent of total cultivated land area). ${ }^{3}$

Data from the Food Security Policy (FSP) project found that the share of farm households receiving remittances varies considerably by region. Southern Shan and the Delta have the lowest shares (12 and 15 percent of farm households, respectively), 30 percent of farm households in the Dry Zone, and 42 percent in Mon State. For those households that receive remittances, the share of total income ranges from 38 to 54 percent. In the Dry Zone in 2017, for example, the average amount remitted was just over one million kyat per year and amounted to 38 percent of total annual household income. In southern Shan, the corresponding numbers were very similar at 1.3 million kyat (40 percent of total annual household income); for Mon State, 1.3 million (54 percent of income); and for the Delta, 1.9 million kyat (43 percent of income). The share of income from remittances is relatively stable across landholding size in the Dry Zone and southern Shan, but higher for the smallest third of farms in Mon State and the Delta. ${ }^{4}$ Although household surveys based on annual

\footnotetext{
${ }^{2}$ Ashok and Naryanan found that only about 50 percent of a universal fertilizer subsidy in India was estimated to have been passed on to farmers from 1980 to 1993 . Mather and Ndyetabula report that when the government of Tanzania paid fertilizer wholesalers a direct subsidy on a limited amount of specific fertilizers, they discovered that they were not able to effectively track the "subsidized" quantities of each type of fertilizer and, thus, could not ensure that the subsidies were passed on to farmers.

${ }^{3}$ It will be important to estimate projections of the number of households and area cultivated as both parameters have likely increased since the 2010 Agricultural Census. We expect that the number of households has likely increased at a faster rate than the expansion in area cultivated, implying a decrease in average farm size over time.

${ }^{4}$ In the Delta, the share of household income for the lowest farm size tercile is almost three times that of the largest tercile -56 percent compared to 20 percent of total household income. The close proximity of the study area to Yangon and, hence, lower costs of out-migration may account for the large share of the smallest landholding tercile households receiving remittance income. In Mon State, the lowest farm size tercile received 59 percent of their income from remittances. In this case, proximity to Thailand makes outmigration an attractive option.
} 
recall data find that remittances are mainly spent on everyday consumption needs, they often fail to capture seasonal patterns in the use of such remittances.

One advantage of a cash transfer targeted to smallholder farmers is that it will help sustain rural employment opportunities for both farm and non-farm households. In the Dry Zone, for example, two thirds of landless households earned an average of one third of their total income working on farms. Furthermore, the strong correlation between access to land and household incomes makes farm size a simple proxy, albeit imperfect, for poverty among households with land. A cash transfer targeted to smallholder farmers will support those farmers who will likely have the most difficulty to finance hired labor and mechanization services to plant and harvest on time. Because a cash transfer offers smallholder farmers the most flexibility to sustain agricultural production levels in the monsoon season, the next section considers implementation modalities to ensure that the transfers reach intended beneficiaries in a timely, inclusive, and efficient manner.

\section{Design considerations for a rapid farm household cash transfer}

The previous section highlighted three interventions to mitigate COVID-19 impacts on agriculture, including a cash transfer program targeted to smallholder farmers. In this section, the following dimensions of the design of such a program are considered in more detail:

- Targeting of beneficiary households;

- Value and scale of the transfer, which determine both the outcomes for rural households and the fiscal burden to the economy;

- Gender considerations;

- Conditionality requirements for beneficiaries;

- Method and frequency of disbursement; and

- Communications strategies about the program to both the general public and to beneficiaries.

We do not provide a comprehensive assessment of each of these factors. However, we suggest options most relevant to the objective of preserving agricultural productivity and access to a nutritious diet for households in agricultural communities across Myanmar.

\section{Targeting of transfer beneficiaries}

The feasibility and desirability of targeting a cash transfer depend on a wide range of factors, but especially the objective of the transfer. The more focused or narrow the objective, the stronger the desirability of targeting. In the case of the COVID-19 threat to the rural economy, decision makers are confronted with multiple potential consequences acting through multiple pathways because of the strong linkages between agriculture, the non-farm rural economy, employment, and nutrition outcomes. The transfers should focus on households that are both vulnerable to economic shocks and whose productivity generates important positive spillovers to the rural economy.

Smallholder farmers are generally poor by any widely accepted measure and they generate important employment opportunities for their neighbors through purchases of labor and services. For this reason, targeting of the cash transfers should be broad. While from an equity perspective there is a case for attempting to target rural households that have lost remittance income streams, given the short time available for such a cash transfer to affect farm household production decisions and the goal of broadly increasing the resilience of smallholder farming households, we recommend targeting smallholder farmers regardless of whether they received remittance streams before the COVID-19 crisis emerged. The time required to develop a more refined targeting strategy could result in delays that undermine the agricultural productivity gains from a rapid response. 


\section{Value and scale of the transfer}

The amount of the cash transfer for each beneficiary and the number of beneficiaries determine the total value of the transfer. The total value of the transfer combined with the administrative costs of delivery represents the fiscal cost to the government budget. The objective is to minimize the fiscal cost while achieving the objectives of the transfer. If even the lowest cost is more than the government can afford, then the amount of the transfer and the number of beneficiaries will need to be scaled in such a way as to get as close to the objective as possible.

A cash transfer in the order of MMK 100,000 (USD 70) per acre would be equivalent to the typical hired labor and mechanization costs for an acre of monsoon crop production. A crop like paddy, which is labor and mechanization intensive, could be higher or lower depending on the planting method. Upland crops, such as maize, sesame, or groundnuts, are even more intensive in the use of hired labor, in part because mechanization options for harvesting are more limited. More detailed cash outlays by zone, crop, and farm operation can be developed, but MMK 100,000 per acre is an approximate starting point for ensuring that the cost of hired services for pre-planting and harvest operations could be covered in the event of additional COVID-19 related household budgetary constraints. A cash transfer of MMK 50,000 per acre would be required at the beginning of the season to accomplish land preparation and planting.

We do not anticipate that the full amount of the transfer will be invested in agricultural production or that it will necessarily be spent on labor and mechanization services. The share of the transfer that individual farmers choose to invest in agriculture versus other types of expenditure, and what inputs they purchase, will vary according to household needs and agricultural production opportunities. Rather, the cash transfer supports their potential to invest in agriculture despite negative financial shocks and other sources of uncertainty they face. We discuss how to influence farmer decisions to increase the share invested in agriculture versus other types of expenditure in the next section.

Using the 2010 Agricultural Census estimates, extending a cash transfer of MMK 100,000 per acre to all smallholder farmers with 5 acres or less would cost approximately USD 400 million, excluding the administrative costs of delivery. An initial payment of MMK 50,000 to ensure timely land preparation and planting would require half of this amount, or USD 200 million, be mobilized immediately. An expansion of the transfer to include all smallholder farmers with 10 acres or less would cost approximately USD 1 billion. As mentioned, these estimates would need to be revised based on projections of household numbers and area since 2010, but they provide a starting point.

Although the cost of a cash transfer of this value and scale seems very high, these costs should be compared to the cost of losses in agricultural productivity that could result from failing to mitigate the COVID-19 threat. Each 1 percent loss in the value of agricultural output represents a direct loss of USD 200 million in output, and a final cost of USD 300 million in GDP, after taking account of indirect losses in employment and services in the rural economy beyond the farm. If the transfer could prevent an average 15 percent drop in agricultural productivity on recipient farms, then a transfer targeted to all farmers under 5 acres would avoid USD 0.9 billion in lost GDP in the coming year, while a transfer to all farmers under 10 acres would avoid USD 2.2 billion in lost GDP. Allowing for a 10 percent administrative cost, a transfer preventing a 15 percent drop in productivity therefore has a short-run benefit-cost ratio of approximately $2: 1$. In addition, there likely will be gains accruing to the transfer in the following year due to the preservation of productive assets, such as livestock or equipment, that might otherwise be sold to cover informal loan obligations. Moreover, these values do not include the very real (but unobserved) economic costs of increased malnutrition among household members associated with losses in output and earnings for the targeted households.

\section{Gender considerations}

Gender considerations permeate the design of interventions to mitigate COVID-19. Women and men migrate in roughly equal proportions, whether domestically or internationally (Thu et al. 2019, Filipski 
et al. 2019). Job losses due to the shuttering of Myanmar's garment sector have disproportionately affected women. When male and female migrants from rural areas return to their homes of origin, they find that employment in agriculture is no less gender delineated. Men tend to focus on tasks where physical strength or operation of machinery is needed, while women focus on tasks requiring dexterity and patience, e.g., transplanting, weeding, picking, and threshing. With a few regional exceptions, significant wage gaps persist between women and men.

Relevant to the proposed cash transfer program is the gender dimension in household decision making (Lambrecht and Mahrt 2019). By default, men are considered the head of the household. Men are traditionally the representatives of their household in the community registry. Consequently, their names are often automatically deemed appropriate on formal documentation of household properties or agricultural land. Women, though, are put in charge of household finances and considered guardians of these resources. Despite the sharing of income and women's oversight on household finances, increasing women's incomes is expected to positively affect their decisionmaking power in the household. Communication strategies and cash transfer delivery modalities need to be sensitive to the potential to increase or decrease women's decision-making power and household welfare.

A second issue of relevance is to ensure access by female-headed farm households to any transfer. Although female-headed households are less likely to own land compared to male-headed households, the gender gap in farm size is relatively small. Agricultural labor is a larger constraint for female-headed farm households - female-headed households hire more labor compared to maleheaded landed households and are more likely to rent or give out land that they own. Cash transfers to female-headed landed households increase their capacity to hire additional agricultural wage labor and to increase their own-production.

Finally, due to the nature of work performed by women wage laborers, the timing of cash transfers could affect their opportunities for employment, as well as adding to their daily workload.

\section{Conditionality requirements for beneficiaries}

Conditionality is frequently employed in cash transfer programs when specific conditions to qualify for continued transfers are deemed necessary to achieve the program's objectives. For example, cash transfers might be made conditional on children attending school when increased child educational enrolment and improved educational outcomes are program objectives, or on attendance at maternal and child health clinics when the objectives include increased coverage of child health interventions or improved mother and child nutritional outcomes. However, the feasibility of such conditionality is dependent on the ability to monitor compliance.

In the current context of a cash transfer to smallholder farm households, effectiveness depends on the share of the transfer used to maintain investment in agricultural productivity and rural employment. In practice, monitoring this would be very costly and intrusive. We therefore recommend that no conditions be imposed on recipients of the transfers. Rather, communication strategies should be employed to encourage compliance with the transfer objectives through a combination of information and moral suasion - not unlike those already being deployed to promote social distancing and hygiene to slow down transmission of the COVID-19 virus.

\section{Method and frequency of disbursement}

The method of disbursement needs to meet several criteria. First, transfers need to reach intended recipients in the full amount. Second, there must be accountability along the delivery chain. Finally, the disbursements must be timely. These are tough goals to meet for a program of this scale with a very short delivery time. Hence the delivery method must rely on existing channels that have proven effective in the past. At the same time, the greater the number of delivery channels, the greater the logistical complexity and potential for compromised objectives or duplication of transfers to the same beneficiary. Finally, a single organization should coordinate and oversee implementation. 
Since the physical transfer of cash allows for potential transmission of the COVID-19 virus, eligible households with access to mobile money should be able to receive transfers through this means. For households that do not have mobile money access, appropriate sanitary measures will need to be employed at disbursement locations. Larger rooms, perhaps unused classrooms, could be used to facilitate social distancing. Washing stations should be available upon entry and exit, and extended hours of operation should be scheduled to minimize queueing.

MADB currently reaches 2 million clients, by far the largest reach of any organization dispersing agricultural loans. The current MADB reform program, and its merger with the Myanmar Economic Bank, incentivizes broader reach into the farming community. The cash transfer program could therefor benefit from MADB's current reach and be a vehicle to allow MADB to extend that reach. Micro-finance institutions with dense delivery networks in areas without MADB coverage could also be utilized. In areas where MADB or micro-finance institutions do not have coverage, then the Department of Agriculture or the General Administration Department could provide an option for delivery. Achieving coverage in areas of conflict or ethnic self-administered zones will inevitably be a challenge, requiring negotiations with local leaders.

For the purposes of proof of eligibility, a range of documentation confirming land use should be accepted, not just the Form 7 land use certificate. These include Forms 105 or 106; La Na 39; land tax receipts; documentation provided by ethnic organizations with jurisdiction; Vacant, Fallow and Virgin (VFV) land use permits; and contracts with village leaders for the use of village land.

In terms of frequency of disbursement of the cash transfer, we recommend a first transfer prior to land preparation and planting, and a second in preparation for harvest and post-harvest crop management. Although a two-stage disbursement process increases the cost to access funds for beneficiaries, it allows time for logistical problems encountered with the first payment to be corrected. More importantly, it enables beneficiaries to manage the funds received in accordance with seasonal demands for labor and mechanization services.

\section{Public and beneficiary communication strategies}

Communication strategies are an essential component of a successful cash transfer program - even more so in the context of a rapid response. Four groups of participants should be reached:

- actors in the disbursement chain,

- transfer beneficiaries,

- private sector service suppliers and extension services, and

- the broader public.

The Farmer TV Channel located in the Department of Agricultural Research of MOALI could be one provider of communication materials. These materials could be distributed through Facebook and by private sector mobile phone application providers, in addition to TV programming. For beneficiaries, it will be important to communicate the purpose of the transfer, the ways in which their appropriate use of the transfer can benefit others in the community, and modalities for accessing the transfer. For private sector service suppliers and extension services, awareness of the program will be useful to them in designing their communication strategies as they compete for the business of transfer recipients and target appropriate extension messages.

\section{Conclusions}

This note draws attention to the urgent need to anticipate and mitigate the threat posed by COVID-19 to Myanmar's agricultural sector and to rural households that depend on it for income and for food and nutrition security. Although loss of remittance income is only one among several types of potential adverse economic impacts on rural households due to COVID-19, the sudden and unexpected loss of such a large share of household income will inevitably be a huge shock for households that are already poor. Unless immediate measures are taken to counteract this shock, 
affected households will be forced to cut back significantly on consumption of food and other essential items and cut back on agricultural inputs and hired labor or mechanization services that are essential to maintain their productivity. This would have noticeable spillover effects in terms of reduced expenditures on goods and labor services supplied by landless rural households and small farmers, even as they have more mouths to feed as a result of returning migrants.

We have evaluated possible options to address the threat, taking note of the short period of time available to support farmers to prepare land and plant their crops on time. Recognizing that no single intervention can address the full range of vulnerabilities faced by rural households, we recommend the following options to ensure adequate support to smallholder farmers:

- Expanded access to seasonal agricultural production credit and flexible post-harvest loan repayment schedules;

- A limited agricultural input subsidy program focused on promotion of quality certified seed for the monsoon season and further evaluation of a range of agricultural input subsidies for the post-monsoon paddy crop in case of low production levels in the monsoon season; and

- An immediate cash transfer to smallholder farmers to maintain agricultural production levels by enabling them to prepare land and to plant and harvest monsoon crops in a timely manner. Despite the high cost of a cash transfer program, there is good reason to expect that the benefits of such support to farm households will outweigh its costs in monetary terms - even more so if the economic benefits from the consequent lower incidence of malnutrition that would result can be measured.

\section{References}

Ambler, K., A. de Brauw, and S. Godlonton. 2017. Relaxing constraints for family farmers: Providing capital and information in Malawi. Unpublished working paper. Washington, DC: International Food Policy Research Institute.

Ambler, K., A. de Brauw, and S. Godlonton. forthcoming. "Cash Transfers and Management Advice for Agriculture: Evidence from Senegal." World Bank Economic Review.

Ashok, G. and S. Narayanan. 1995. "Subsidy Syndrome in Indian Agriculture." Economic and Political Weekly, (30) 39: A93-A102.

Block S., L. Kiess, P. Webb, S. Kosen, R. Moench-Pfanner, M.W. Bloem, and C.P. Timmer. 2004. "Macro shocks and micro outcomes: Child nutrition during Indonesia's crisis." Economics and Human Biology, 2: 21-44.

Boughton, D., S. Makhija, M. Maredia, D. Mather, D. Megill, D. Ortega, E. Payongayong, L. Plataroti, D.J. Spielman, M. Thijssen, and M.T. Win. 2020. Variety Adoption and Demand for Quality Seed in the Dry Zone of Myanmar. Feed the Future Innovation Lab for Food Security Policy Research Paper. East Lansing, MI: Michigan State University.

de Wit, P. and A.-L. Noack. 2019. Policy Effectiveness Analysis. MOALI-EU-FAO FIRST Policy Facility. Nay Pyi Taw, Myanmar: Food and Nutrition Security Impact, Resilience, Sustainability and Transformation (FIRST) program.

Filipski, F., and J. Taylor. 2012. "A Simulation Impact Evaluation of Rural Income Transfers in Malawi and Ghana." Journal of Development Effectiveness, 4:1, 109-129.

Headey D., and O. Ecker. 2013. "Rethinking the measurement of food security: From first principles to best practice." Food Security, 5: 327-343.

Hein, A. and P. Minoletti. 2020. Coronavirus Response Policy Needs and Opportunities. Unpublished policy brief.

International Food Policy Research Institute (IFPRI) and Michigan State University (MSU). 2020. "Maintaining food and nutrition security in Myanmar during the COVID-19 crisis: Lessons from India's lockdown." Myanmar SSP Policy Note 01. Washington, DC: IFPRI. https://doi.org/10.2499/p15738coll2.133678

Lambrecht, I. and K. Mahrt. 2019. Gender and Assets in Rural Myanmar: A Cautionary Tale for the Analyst. IFPRI Discussion Paper 1894. Washington, DC: International Food Policy Research Institute (IFPRI).

Mahrt, K., D. Mather, A. Herforth, and D. Headey. 2019. Household Dietary Patterns and the Cost of a Nutritious Diet in Myanmar. Feed the Future Innovation Lab for Food Security Policy Research Paper 135. East Lansing, MI, USA: Michigan State University.

Mather, D. and D. Ndyetabula. 2016. "Assessing the Drivers of Tanzania's Fertilizer Subsidy Programs from 2003-2016: An Application of the Kaleidoscope Model of Policy Change." Feed the Future Innovation Lab for Food Security Policy Research Paper 34.

World Bank. 2020. East Asia and Pacific in the Time of Covid-19. East Asia and Pacific Economic Update (April). Washington, DC: World Bank. 


\section{ABOUT THE AUTHORS}

Duncan Boughton is a Professor of International Development at Michigan State University (MSU), Policy Advisor for the Ministry of Agriculture, Livestock and Irrigation of the government of Myanmar, and a lecturer at Yezin Agricultural University, based in Nay Pyi Taw, Myanmar. Joseph Goeb is a Research Associate in the Department of Agricultural, Food, and Resource Economics of MSU, based in Yangon. Isabel Lambrecht is a Research Fellow in the Development Strategy and Governance Division of the International Food Policy Research Institute (IFPRI) and program leader of IFPRI's Myanmar Strategy Support Program, based in Yangon. David Mather is an Assistant Professor in the Department of Agricultural, Food, and Resource Economics of MSU, based in Virginia, USA. Derek Headey is a Senior Research Fellow with the Poverty, Health, and Nutrition Division of IFPRI, based in Yangon.

\section{ACKNOWLEDGMENTS}

This work was undertaken as part of the Myanmar Agriculture Policy Support Activity (MAPSA) through the CGIAR Research Program on Policies, Institutions, and Markets (PIM) led by the International Food Policy Research Institute (IFPRI). Funding support for this study was provided by the CGIAR Research Program on Policies, Institutions, and Markets, the United States Agency of International Development (USAID) and the Livelihoods and Food Security (LIFT) Fund. This Policy Note has not gone through IFPRI's standard peer-review procedure. The opinions expressed here belong to the authors, and do not necessarily reflect those of IFPRI, MSU, USAID, PIM, or CGIAR.

INTERNATIONAL FOOD POLICY RESEARCH INSTITUTE

1201 Eye St, NW I Washington, DC 20005 USA T. +1-202-862-5600 | F. +1-202-862-5606 ifpri@cgiar.org www.ifpri.org | www.ifpri.info

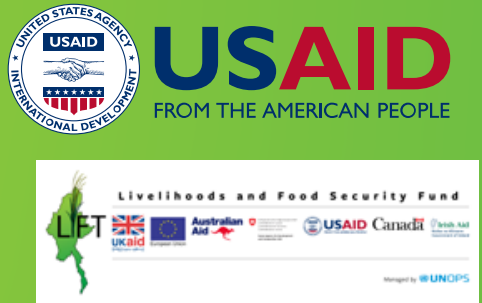

The Myanmar Strategy Support Program (Myanmar SSP) is led by the International Food Policy Research Institute (IFPRI) in partnership with Michigan State University (MSU). Funding support for Myanmar SSP is provided by the CGIAR Research Program on Policies, Institutions, and Markets; the Livelihoods and Food Security Fund (LIFT); and the United States Agency for International Development (USAID). This publication has been prepared as an output of Myanmar SSP. It has not been independently peer reviewed. Any opinions expressed here belong to the author(s) and do not necessarily reflect those of IFPRI, MSU, LIFT, USAID, or CGIAR. 